\title{
Open (wide) access
}

\author{
Stephen Hancocks OBE \\ Editor-in-Chief
}

Send your comments to the

Editor-in-Chief,

British Dental Journal

64 Wimpole Street,

London,

W1G 8YS

Email bdj@bda.org
Open access $(\mathrm{OA})$ is one of those terms which tend to get tossed around rather casually in publishing and electronic media circles without necessarily being well defined, or, consequently understood. Excitingly, the $B D J$ is about to begin offering the opportunity to publish open access research papers and so it is timely to explain what this means, and as importantly what it does not mean.

In the context of journal publishing $\mathrm{OA}$ is the web-based electronic distribution of peer reviewed journal literature allowing completely free, unpaid and unrestricted access by all, not just researchers, practitioners or subscribers. The most important feature to note is that, despite the name, it does NOT mean that all content of the $B D J$ becomes openly available on the internet to all for free. It means that the facility will exist for those research papers which the author(s) and/or an organisation funding their research wish to have openly available on the $B D J$ website and are prepared to pay the cost of doing so.

The starting point for OA was in 2001 when 34,000 scholars from around the world signed 'An Open Letter to Scientific Publishers' calling for 'the establishment of an online public library that would provide the full contents of the published record of research and scholarly discourse in medicine and the life sciences in a freely accessible, fully searchable, interlinked form'. Scientists signing the letter also pledged not to publish in or peer review for non-open access journals. This led to the establishment of the Public Library of Science which is now the largest publisher of open access science research.

At a meeting in Budapest the same year a declaration was signed stating that: 'removing access barriers to this literature will accelerate research, enrich education, share the learning of the rich with the poor and the poor with the rich, make this literature as useful as it can be, and lay the foundation for uniting humanity in a common intellectual conversation and quest for knowledge.'

\section{HOW DOES IT WORK?}

The 'hybrid model', the term for the combination of OA and nonOA content that the $B D J$ will offer, gives authors of accepted research articles the choice to pay an article processing charge enabling their article to be made open access immediately upon publication. As well as covering the costs of copyediting, typesetting and web hosting this one-off sum allows authors to post the final, published PDF version of their article on their personal website, institutional repository or other free public server immediately upon publication.
As far as the process of submission to the $B D J$ and of peer review is concerned there will be no change at all. The open access requirement of the author(s)/funding body will not be revealed by them at the point of submission of a paper, so no bias in favour of such papers will be possible in the peer review process. As and when a paper is accepted if those submitting it reveal that open access is a requirement, only then will payment follow for the facility.

The intention is that, apart from wishing to participate in the increased accessibility of scientific knowledge, by making the OA facility available in the $B D J$ it will attract additional submissions which to date will not have not have been sent to us for consideration. This has become even more important in recent years with the huge increase in unique visitors from around the world to the $B D J$ 's website; in the region of 100,000 per month. There is an increasing swell of opinion that publicly-funded research should be publicly available on publication. Several important institutions and funding bodies are mandating that the research they fund is made OA on publication, and are specifically setting aside funding for this. These include the National Institutes of Health and Harvard University among others in the USA, and the Wellcome Trust and UCL among others in the UK.

The $B D J$ has in the past published research funded by these bodies and it is likely that more and more public funders and institutions will follow suit in future. By offering authors the OA option, the $B D J$ will enable them to automatically comply with their funder mandate.

$\mathrm{OA}$ is also completely compatible with copyright law, which gives the copyright holder the right to make access open or restricted. OA journals can either let authors retain copyright or ask them to transfer copyright to the publisher. In either case, the copyright holder will consent to open access for the published work. When the publisher holds the copyright, it will consent to OA directly. When authors hold the copyright, as is the case for $B D J$ articles, they will ensure open access by signing a license to the publisher authorising OA.

By offering $\mathrm{OA}$ as part of the $B D J$ 's services it will underline the journal and the BDA's support of dental research to the community and ensure that the $B D J$ is available as a publication outlet to researchers no matter how research funding develops in future. We believe that this will be a significant step forward for the journal and is a demonstrable additional benefit of our renewed and extended partnership with the Nature Publishing Group whose expertise has been of great value in this development.

DOI: 10.1038/sj.bdj.2012.269 